\title{
O PODER CONSTITUINTE DO POVO NO BRASIL: UM ROTEIRO DE PESQUISA SOBRE A CRISE CONSTITUINTE
}

Gilberto Bercovici

\section{Breves considerações teóricas sobre o poder constituinte do povo}

O presente texto não pretende ser mais do que um breve roteiro de pesquisa sobre a questão do poder constituinte no Brasil. Esta pesquisa se faz necessária tendo em vista, passados 25 anos da Assembleia Nacional Constituinte de 1987-1988, a permanência do tratamento acrítico, formalista e repetitivo da doutrina jurídica brasileira recente concernente a este tema, central, em minha opinião, para a compreensão das relações complexas entre Estado, constituição, soberania, democracia e política ${ }^{1}$.

A doutrina jurídica tradicional entende que o povo e o poder constituinte não têm lugar no direito público, por não serem "categorias jurídicas". O que se esquece com esta visão é o simples fato de que as questões constitucionais essenciais são políticas. Tentar separar o conceito de consti-

\footnotetext{
${ }^{1}$ Uma pesquisa mais ampla e aprofundada sobre as relações entre Estado, soberania, constituição, política, poder constituinte, democracia e Estado de exceção foi publicada em Bercovici (2008).
} 
tuição do conceito de poder constituinte significa excluir a origem popular da validade da constituição e esta validade é uma questão política, não exclusivamente jurídica. A doutrina do poder constituinte é, antes de tudo, um discurso sobre o poder constituinte, exercendo o papel de mito fundador e legitimador da ordem constitucional. Para utilizar a expressão de Ernst-Wolfgang Böckenförde, o poder constituinte é um "conceito limite" do direito constitucional. Não se trata da norma fundamental hipotética de Hans Kelsen ou de direito natural, mas de uma força política real que fundamenta a normatividade da constituição, legitimando-a (Böckenförde, 1992a, pp. 92-4; Isensee, 1992, pp. 159-62; Klein, 1996, pp. 89, 191-9; Müller, 1995, pp. 18, 23, 54-6, 65-8, 77-8; Henke, 1980, pp. 194-8, 204-8, 210-11; Palombella, 1997, pp. 21-38).

O poder constituinte é manifestação da soberania. É um poder histórico, de fato, não limitado pelo direito. 306 Como tem caráter originário e imediato, o poder constituinte não pode ser reduzido juridicamente. Não pode ser limitado, embora não seja arbitrário, pois tem "vontade de constituição". A titularidade do poder constituinte deve corresponder ao titular da soberania. Historicamente, de acordo com Nelson Saldanha (1986), isso significa indagar como o povo chegou à pretensão desta titularidade e como viabilizar esta pretensão, pois a soberania popular se refere essencialmente ao povo como titular do poder constituinte. Desde a Revolução Francesa, o poder constituinte do povo é visto como a verdadeira forma da soberania popular. Afinal, com a teoria do poder constituinte do povo durante a Revolução Francesa, demonstrou-se que o povo estava sendo chamado a decidir coletivamente sobre a sua forma política, regenerando e constituindo novamente o poder (Steiner, 1966, pp. 66-7; Saldanha, 1986, pp. 67-8, 72-7; Böckenförde, 1992a, pp. 94-100, 107-12; 1992b, pp. 293-5; Beaud, 1994, pp. 325-8). 
O poder constituinte pode ser pensado em termos diretamente fáticos, ou seja, como o povo, em sua totalidade e sem intermediários, cria a constituição para si e permanece como instância decisiva para a manutenção, alteração ou substituição da constituição, instituindo, segundo Müller (1995), uma democracia plebiscitária sem restrições ${ }^{2}$. No Estado constitucional, no entanto, o poder constituinte nunca é pensado como um poder diretamente proveniente e exercido pelo povo, mas apenas em termos indiretos, representativos, como um poder exercido de forma mediada pelo povo. Deste modo, a ideia de que o poder constituinte originário está no povo é inseparável, historicamente, da ideia de representação em assembleia constituinte (Müller, 1995, pp. 23-4) ${ }^{3}$. No entanto, quem convoca o poder constituinte, segundo Faoro, não é o poder estatal. Este apenas instrumentaliza, sem subordinar, a vontade popular, restituindo o poder ao povo (Faoro, 1986, pp. 84-5, 89-90).

O poder constituinte do povo é visto por boa parte do pensamento político e constitucional como, nas palavras de Cantaro (1994), um "terribile potere", do qual sempre se desconfia, contestando sua plausibilidade, legitimidade

\footnotetext{
${ }^{2}$ A crítica que também pode ser feita ao discurso do poder constituinte é a da utilização do povo no lugar de Deus para legitimar o poder. A representação unitária do povo é harmonizadora, tentando justificar as contradições existentes. A constituição não é identificada com um grupo ou como um compromisso, mas como oriunda do povo em sua totalidade (Müller, 1995, pp. 12-3, 15-6, 23-4, 34, 39-41). Para a visão do povo como um conceito complexo, não unitário, ver Comparato (1989, pp. 69-70).

${ }^{3}$ Radicalizando esta linha de raciocínio, Klaus von Beyme afirma que o poder constituinte é sempre mediado. A identidade entre assembleia constituinte e povo é uma ficção; portanto, praticamente todas as constituições seriam de origem oligárquica (Beyme, 1968, pp. 7-11, 55). As funções não constituintes que as assembleias constituintes muitas vezes exercem, como, por exemplo, atuar como poder legislativo ordinário simultaneamente à função constituinte, foram denominadas, por Arnaud Le Pillouer, de "pouvoir instituant" (Le Pillouer, 2005).
} 
e cientificidade. $\mathrm{O}$ direito tem dificuldades em entender a produção jurídica como proveniente de um poder "de fato", extraordinário e livre na determinação de sua própria vontade. $O$ poder constituinte contradiz as pretensões do ordenamento jurídico de estabilidade, continuidade e mudança dentro das regras previstas. A aversão dos juristas à soberania popular e à teoria do poder constituinte do povo, segundo Cantaro (1994), vem de uma visão política e filosófica que atribui as origens do totalitarismo à soberania popular. A democracia absoluta fatalmente degeneraria para a violência, o terror e o totalitarismo. $\mathrm{E}$ isso teria ocorrido desde a aplicação da concepção absoluta de soberania popular de Rousseau pelos jacobinos durante a Revolução Francesa (Cantaro, 1994, pp. 139-45). Para os positivistas, o poder constituinte é um poder natural ( näturliche Macht), um poder pré-jurídico ou metajurídico. Como, então, o poder constituinte não é jurídico, não faz 308 parte das preocupações dos juristas. E a discussão atual sobre poder constituinte limita-se a um debate sobre os limites da revisão constitucional (Steiner, 1966, pp. 31-6; Henke, 1968, p. 180; 1980, pp. 181-2; 1992, p. 276; Klein, 1996, pp. 115-21). Para Pedro de Vega García, é sintomático e revelador o fato de que a teoria do poder constituinte, enquanto máxima expressão do princípio democrático e questão central da problemática constitucional, tenha se convertido em tema menor para a doutrina constitucional (García, 1998, p. 47).

A grande dificuldade dos juristas, na realidade, deve-se ao fato de que o poder constituinte é um poder sem limites, que, portanto, não pode ser caracterizado juridicamente. Afinal, o direito não costuma operar com termos absolutos, pois trata de limitação e relativização. A única autolimitação do poder constituinte que é compatível com sua condição de soberano é uma autolimitação procedimental, não material. Ou seja, podem ser criadas regras 
sobre a formação da vontade soberana, mas não sobre o conteúdo dessa vontade (Reyes, 1989, pp. 29-30, 34-5) ${ }^{4}$.

O poder constituinte, assim, não tem forma predeterminada de manifestação e carece de limites jurídicos. Se os tivesse, não poderia criar uma nova ordem, mas se moveria no marco da ordem preexistente, não seria constituinte, seria constituído. A tese de que o poder constituinte deve cumprir os valores da democracia liberal, segundo Alessandro Pace (1997), apresenta como jurídico algo que é político e confunde a constituição, fenômeno historicamente condicionado, com o constitucionalismo, filosofia política. Para Friedrich Müller (1995), o poder constituinte não está vinculado normativamente, apenas culturalmente. Uma determinada normatividade (como a do artigo 16 da Declaração dos Direitos do Homem e do Cidadão, de 1789) não pode ser transferida para outra área de vigência de uma cultura constitucional distinta, nem transcender o seu campo histórico de atuação (Müller, 1995, pp. 72-3; Pace, 1997, pp. 105-8; Palombella, 1997, pp. 45-6).

O poder constituinte atua de forma permanente. Ele se refere ao povo concreto, com autoridade e força para estabelecer a constituição, manter sua pretensão normativa e revogá-la. A manutenção ou erosão da normatividade constitucional está ligada à permanência do poder constituinte, fonte da sua força normativa (Faoro, 1986, p. 90, 95; Böckenförde, 1992a, p. 100; 1992b, p. 295; Beaud, 1994, pp. 414-23; Bonavides, 1998 pp. 162-4; Müller, 1995, pp. 36-8; Palombella, 1997, pp. 35-6 e Fioravanti, 1998, pp. 56-7).

Como já afirmei anteriormente, a maior parte da doutrina jurídica negligencia o poder constituinte. As próprias constituições o mascaram, aparecendo marginalmente no

\footnotetext{
${ }^{4}$ Na visão de Palombella, por sua vez, o poder constituinte não é uma simples força extrajurídica, mas um conceito jurídico cujo conteúdo depende das suas características democráticas. É a expressão da autolegislação popular, ou seja, do ato de dar-se uma constituição (Palombella, 1997, pp.39-45, 47).
} 
texto constitucional. As constituições, como observa Müller (1997, pp. 18-21), recorrem ao povo, mas não falam sobre o seu poder. O objetivo dessa menção é sempre a legitimação do sistema político. No mesmo sentido, Comparato afirma que a solenidade da fórmula "todo o poder emana do povo" encobre o efetivo recuo histórico da soberania popular, com a tentativa de eliminação de todo poder ativo do soberano (Comparato, 1989, pp. 68-9). Deste modo, as constituições ignoram a centralidade do poder constituinte para o constitucionalismo moderno, como poder onipotente, fonte primária e decisão política fundamental sobre a forma de dar unidade política a um povo. Para Portinaro (1996, pp. 25-8), essa negação do poder constituinte pelo constitucionalismo mostra que a história do Estado moderno é a história de um Estado legislativo que progressivamente expropria o legislador. O poder constituinte seria real, para Friedrich Müller (1995, p. 16), se os

310 poderes constituídos fossem exercidos pelo próprio poder constituinte. O Estado constitucional, no entanto, é contrário a isso. O povo utiliza seu poder para fundar os outros poderes que, a partir de sua criação, passam a dispor sobre o povo. Não há poder constituinte onde o povo é alienado do poder (Beaud, 1994, pp. 210-20).

\section{A reflexão sobre o poder constituinte do povo na doutrina jurídica brasileira}

O poder constituinte, que já foi, inclusive, denominado "tema nebuloso" (Horta, 1999, p. 25), é tratado pela doutrina brasileira recente a partir da transposição da visão europeia, notadamente da experiência francesa. A monografia de Manoel Gonçalves Ferreira Filho (1999, pp. 10-7) é inteiramente baseada em parte da exposição de Sieyès. Raul Machado Horta recupera, entre outros, Carré de Malberg e Georges Burdeau (Horta, 1999, pp. 26-9). Paulo Bonavides, por sua vez, embora tenha uma reflexão original, como 
veremos adiante, destaca o poder constituinte a partir do pensamento de Sieyès, Carré de Malberg, Eduard Laboulaye e do alemão Egon Zweig, que, no início do século XX, fez uma clássica análise da Assembleia Constituinte Revolucionária francesa (Bonavides, 1998, pp. 120-39) ${ }^{5}$.

Outros autores buscaram uma explicação teológica de poder constituinte, comparando-o ao poder divino de criação (Britto, 2003, pp. 5-28). Embora não esteja citado expressamente no trecho indicado, a semelhança desta visão com a concepção decisionista da teologia política de Carl Schmitt $(1993,1996)$ não parece ser apenas coincidência. O poder constituinte, para Carl Schmitt, é a origem concreta da forma política; é a própria exceção, sendo impossível de ser descrito em termos normativos. Seu fundamento é a vontade política existencial, cujo sujeito, na democracia, é o povo. A unidade política é formada pela decisão política fundamental do poder constituinte, que é preexistente enquanto ser concreto, mas que só vem a existir efetivamente na decisão existencial. $O$ povo, para Schmitt, está acima e além da constituição, entendendo, portanto, que o poder constituinte não se esgota, permanece existindo ao lado e acima da constituição, o que justifica a célebre distinção entre constituição e lei constitucional (Schmitt, 1996, p. 43; 1993, pp. 9-10, 20-5, 75-87, 91-9, 238; Hofmann, 2002, pp. 123-39; Breuer, 1984, pp. 50916; Pasquino, 1988, pp. 378-84; Cristi, 2000, pp. 1749-60; Thiele, 2003, pp. 215-51) ${ }^{6}$.

\footnotetext{
${ }^{5}$ Sobre Egon Zweig (1909), cumpre ressaltar que boa parte dos autores considera este seu livro, em conjunto com as obras de Robert Redslob (1912) e de Karl Loewenstein ([1922] 1990) uma espécie de "trilogia" alemã sobre o poder constituinte (Klein, 1996, pp. 99-100).

${ }^{6}$ Sobre as similaridades e diferenças das concepções de poder constituinte de Sieyès e de Carl Schmitt, ver Steiner (1966, pp. 216-9), Galli (1996, pp. 582-3, 6089) e Thiele (2003, pp. 166-77). Para Schmitt, o povo é a instância última e suprema, embora o termo "povo" seja ambíguo, pois se refere, ao mesmo tempo, ao sujeito do poder constituinte e a um poder constituído (Schmitt, 1927, pp. 8, 32-3).
} 
Há, ainda, os que buscam entender o poder constituinte a partir da teoria discursiva de Jürgen Habermas ${ }^{7}$ ou das concepções inspiradas em Spinoza do italiano Antonio Negri. Para Negri (2002, pp. 8-24, 26-8, 37-9, 45-7, 54, 374-7, 384, 386-7, 391-414), o poder constituinte é ontológico, um produto da descontinuidade radical, não podendo ser vinculado à soberania, que é o seu oposto. A soberania é poder constituído, que busca bloquear e neutralizar o poder constituinte. $\mathrm{O}$ poder constituinte cria a democracia, o governo absoluto da multidão, contraposto ao governo limitado do constitucionalismo. A concepção jurídica de poder constituinte é, segundo Negri, contraditória, pois ignora seu caráter onipotente de potência da multidão. A democracia é a negação do constitucionalismo como poder constituído. $\mathrm{O}$ poder constituinte não esgota seus efeitos, é um movimento ininterrupto de construção do novo. Para Negri, o poder constituinte não vem depois da política, ele vem antes, é a 312 própria definição de política. O problema essencial da concepção de poder constituinte de Negri é a sua tentativa de desvincular poder constituinte de soberania, que ele entende como contrapostos. O poder constituinte não é oposto à soberania, pelo contrário, é a sua manifestação máxima. Sem soberania, o conceito de poder constituinte de Negri perde a base material de sustentação e se torna algo etéreo, metafísico ${ }^{8}$.

Boa parte do debate recente em torno do poder constituinte no Brasil deu-se por textos ditos "de ocasião", elaborados durante o processo de redemocratização e reconstitucionalização do país na década de 1980. Embora estes textos muitas vezes tenham tentado trazer algumas questões

\footnotetext{
${ }^{7}$ Marcelo Cattoni Oliveira (2006) tenta compreender o poder constituinte utilizando as categorias habermasianas.

${ }^{8}$ Para outra crítica à teoria do poder constituinte de Negri, ver Agamben (1995, pp. 50-1). A obra de Antonio Negri influenciou a reflexão de Francisco de Guimaraens $(2004)$.
} 
pontuais interessantes ou inovadoras, estão demasiado circunscritos ao debate da convocação, instalação e discussões da Assembleia Nacional Constituinte de 1987-1988 (Dallari, 1984; Bonavides, 1987; Grau, 1985; Ferraz Júnior, 1986; Bierrenbach, 1986; Comparato, 1986; Silva, 2000, pp. 17-113). Aliás, uma grande lacuna é a falta de estudos sobre o processo constituinte brasileiro, em geral ${ }^{9}$. Há, ainda, aqueles que, por afirmarem estar tratando do direito constitucional positivo, sequer tratam do tema do poder constituinte, salvo para mencionar o poder de reforma constitucional e seus limites (Silva, 2000a, pp. 66-7) ${ }^{10}$.

Embora as influências teóricas sejam distintas, com inegável supremacia francesa, podemos afirmar que, para a quase totalidade da doutrina brasileira, não existe uma reflexão sobre o poder constituinte do povo. Poder constituinte é "apenas" o poder do povo dar-se uma constituição, como se a questão fosse tão simples de ser resolvida assim, ainda mais no caso complexo do Brasil. O entendimento brasileiro sobre poder constituinte parece dar razão à afirmação de Manoel Gonçalves Ferreira Filho, que recomenda o abandono da teoria do poder constituinte: "Deixe-se de lado a teoria do Poder Constituinte, utópica e metafísica, que aponta apenas um paradigma (rarissimamente seguido)" (Ferreira Filho, 1995, p. 142).

Da afirmação cética de Manoel Gonçalves Ferreira Filho, no entanto, há um ponto fundamental a ser explorado: a teoria do poder constituinte aponta um paradigma, rarissimamente seguido. É justamente este o problema da visão brasileira sobre poder constituinte. $\mathrm{O}$ paradigma fran-

\footnotetext{
${ }^{9}$ Uma das melhores pesquisas sobre os debates da Assembleia Nacional Constituinte de 1987-1988 é de um estrangeiro, Eugster (1995). Outro trabalho importante é a análise de Pilatti (2008). Merecem destaque, ainda, o levantamento histórico de Wachowicz (2000) e a pesquisa sobre a participação popular na Constituinte desenvolvida por Barroso (1999).

${ }^{10}$ Em sentido contrário, defendendo a importância jurídica do poder constituinte, ver Tavares (2003, pp. 34-5).
} 
cês do século XVIII foi elevado a uma espécie de manual de instruções de como se deve compreender o poder constituinte. A transposição da visão francesa para o Brasil gerou uma discussão doutrinária estéril, sem qualquer vinculação com nossa experiência política e constitucional.

\section{A crise constituinte}

As exceções a este quadro, com contribuições originais que buscam compreender a realidade brasileira, são algumas das análises de Nelson Saldanha e a concepção de crise constituinte, formulada por Paulo Bonavides. Nelson Saldanha, após bem fundamentada análise sociológica do poder constituinte $^{11}$, destaca o seu entendimento do poder constituinte como um poder "transconstitucional", ou seja, que prossegue através das constituições que gera, permanecendo latente, sem se transformar em poder constituído (Saldanha, 1986, pp. 83-6) ${ }^{12}$. Este é um dos raros momen-

314 tos de nossa doutrina em que se busca compreender a permanência e a descontinuidade do poder constituinte, para além dos formalismos.

A interpretação mais original de poder constituinte, no entanto, é de Paulo Bonavides. Para este autor, a constante contestação da legitimidade do poder e da ordem social no Brasil é um reflexo não da crise de constituição, mas da "crise constituinte", que diz respeito à inadequação do sistema político e da ordem jurídica ao atendimento das necessidades básicas da ordem social. O problema constitucional brasileiro está fundado na contradição entre a constituição formal e a constituição material. Esta contradição geraria

\footnotetext{
${ }^{11}$ Para outras tentativas de análise sociológica do poder constituinte, ver Faoro (1986), Dantas (1985) e Farias (1988). Em relação a Faoro (1986), sua fina argumentação ressalta a usurpação e a recuperação da legitimidade política pela manifestação do poder constituinte do povo.

${ }^{12}$ Marcelo Cattoni Oliveira afirma, corretamente, que o projeto constituinte está sempre inconcluso, está sempre em construção permanente (Oliveira, 2006, pp. 49-63, 88-9).
} 
uma crise permanente, pois não teria sido superada, formal e materialmente, por nenhuma de nossas constituições (Bonavides e Andrade, 1991, pp. 5-12). O poder constituinte do povo, na crise constituinte, é condenado a tornar-se um mero símbolo formal, referendando, segundo Bonavides (1998, pp. 169-71), os conteúdos constitucionais de outro poder constituinte, o das forças reais de poder, para utilizarmos a expressão de Lassalle (1907, pp. 41-2, 45-6, 51, 68). Esta crise não se exaure com a adoção de uma nova constituição, pois diz respeito ao próprio Estado e à sociedade, manifestando-se com a contraposição entre a constituição e a realidade social. A crise constituinte é uma crise do próprio poder constituinte, que não se resolveu desde as origens do Estado brasileiro (Bonavides, 1998, pp. 164-71, 346-52; 1999, pp. 40-4, 75-9, 157-63).

A concorrência histórica entre "poderes constituídos" e "poder constituinte" que, para Bonavides (1998; 1999), seria uma das causas da crise constituinte, não tem o mesmo sentido da velha e célebre distinção criada por Sieyès (1989), ainda em 1789, entre pouvoir constituant e pouvoirs constitués. Na realidade, trata-se do enfrentamento entre poderes de exceção, dos poderes de fato (seja do poder político "constituído", seja do poder "constituinte") entre si e com as circunstâncias históricas, políticas, sociais e econômicas de cada momento específico.

O poder constituinte do povo é a grande manifestação da soberania. Neste sentido, é um poder absoluto, o que significa incontrolável, não necessariamente totalitário ou autoritário (Beaud, 1993, p. 36). As limitações ao poder constituinte não são fruto de concepções jusnaturalistas (como determinados discursos sobre direitos humanos $)^{13}$, mas de ordem concreta e estrutural. O poder constituinte

\footnotetext{
${ }^{13}$ Para uma defesa desta posição de limitação do poder constituinte originário pelos direitos humanos, com a qual não concordo, ver Pinto (1994, pp. 92-7, 139-51).
} 
do povo é um poder absoluto, mas exercido dentro das condicionantes culturais, históricas e materiais que encontra.

A questão na periferia está ligada aos limites históricos e estruturais que o poder constituinte encontra para se manifestar plenamente como formação da vontade soberana do povo. O problema central, ignorado pela maior parte de nossos doutrinadores, é o fato de que a soberania brasileira, como soberania de um Estado periférico, é uma soberania bloqueada, ou seja, enfrenta severas restrições externas e internas que a impedem de se manifestar em toda sua plenitude (Bercovici, 2004a, pp. 159, 163-166, 178-180; 2004b, pp. 267-77).

Quem percebeu a especificidade da manifestação do poder constituinte do povo em um país como o Brasil foi, em 1985, Nelson Saldanha (1986, pp. 15-23), que propôs o debate e a reflexão sobre o poder constituinte em um país no qual a soberania popular nunca havia se manifes316 tado plenamente e que nunca possuiu soberania plena ${ }^{14}$. Da mesma forma, Paulo Bonavides sustenta que a crise constituinte costuma atingir os países subdesenvolvidos. E, em minha opinião, Bonavides conseguiu sintetizar a questão do poder constituinte e da crise constituinte na seguinte afirmação:

Ela [a crise constituinte] é indicativa da inferioridade ou da insuficiência de soberania das diversas Constituintes, cujas limitações tácitas ou expressas nos conduzem inarredavelmente a irretorquível conclusão de que, em verdade, jamais tivemos uma Assembleia Nacional Constituinte, dotada de liberdade, exclusividade e plenitude de poderes, pelo menos daqueles com que a teoria revolucionária do século XVIII sempre armara esses

\footnotetext{
${ }^{14}$ Para Wachowicz (2000, p. 200), seguindo uma linha próxima às de Saldanha e Bonavides, o "problema constituinte" brasileiro reside no ostensivo desrespeito à soberania popular.
} 
parlamentos, a fim de que, providos da suprema vontade da Nação, pudessem refazer as instituições desde os seus fundamentos (Bonavides, 1998, pp. 351-52).

\section{Crise constituinte, construção da nação e poder constituinte do povo}

A crise constituinte, portanto, está ligada aos bloqueios à manifestação da soberania plena no Brasil. É possível, ainda, tentar relacionar a questão do poder constituinte do povo com a interrupção da construção da nação, tese defendida por Celso Furtado $(1992,1999)^{15}$. Mas, antes, é preciso definir o significado de nação para Celso Furtado, que não tem relação alguma com a concepção de Sieyès.

Para Sieyès, assim como para boa parte dos autores do século XVIII, como Adam Smith, a nação tem um significado econômico. A nação é composta por todos aqueles que contribuem para o progresso econômico, produzindo bens e valores para o mercado. A nação não é abstrata, sendo definida como um todo social integrado pelo conjunto de indivíduos dispersos que produzem e trocam no mercado e que querem proteger suas relações econômicas. O que unifica o Terceiro Estado é o interesse comum em realizar e estender seus direitos, concebidos como meios de satisfazer as suas necessidades. A nação exclui os privilegiados, que não participam no trabalho, como a nobreza, sendo constituída pelo conjunto dos produtores de bens e valores. Por isso, o Terceiro Estado é uma nação completa, autossuficiente e autônoma. O papel da nação é redigir uma constituição para manter a possibilidade de evolução do sistema político em conformidade com os interesses econômicos (Sieyès, 1989; Bastid, 1970, pp. 350-6; Rosanvallon, 2002, pp. 85-6, 107, 115-8; Clavreul, 1987, pp. 48-50; Máiz, 1991,

\footnotetext{
${ }^{15}$ Ainda sobre a concepção de Celso Furtado da construção nacional interrompida, ver Fiori (2000).
} 
pp. 53-6, 59; Negri, 2002, pp. 265-7, 273-4; Pasquino, 1998, pp. 14, 55-6, 61-2) ${ }^{16}$.

Já Celso Furtado entende a construção da nação no Brasil como um processo de internalização dos centros de decisão econômica, com a inclusão da população e a garantia da homogeneização social ${ }^{17}$. A homogeneização social, segundo Celso Furtado, é um elemento fundamental para a cidadania e para a democracia, no mesmo sentido em que, ainda em 1928, já havia destacado Hermann Heller (1992b, pp. 427-31).

Feita esta distinção, como é possível vincular a constituição, fruto do poder constituinte do povo, com a construção da nação? A constituição tem vários significados e funções, como bem demonstrou a exposição célebre de Hans Peter Schneider (1974, pp. 68-75). Dentre estas, no entanto, merece destaque a visão, fundada em Rudolf Smend, da constituição como um símbolo da unidade 318 nacional $^{18}$. Herbert Krüger (1973, pp. 247-9, 272) vai além e entende a constituição como um projeto de integração nacional, o que, no nosso caso, seria interessante para compreender a ideia da constituição como um projeto nacional de desenvolvimento.

Uma hipótese de trabalho seria a de tentar entender se os Estados que buscam terminar a sua construção nacional, como o Brasil, adotam a ideia da constituição como

\footnotetext{
${ }^{16}$ Sobre a influência dos fisiocratas em Sieyès e em sua definição econômica de nação, ver, ainda, Bastid (1970, pp. 310-2).

${ }^{17} \mathrm{Na}$ definição de Celso Furtado: "O conceito de homogeneização social não se refere à uniformização dos padrões de vida, e sim a que os membros de uma sociedade satisfazem de forma apropriada as necessidades de alimentação, vestuário, moradia, acesso à educação e ao lazer e a um mínimo de bens culturais" (Furtado, 1992, p. 38). Em um sentido próximo, Hermann Heller afirmava que não poderia haver comunidade nacional se não partisse da comunidade social de um povo (Heller, 1992a, pp. 442, 466-8, 472-7, 501).

${ }^{18}$ Para uma interpretação da constituição como símbolo da unidade nacional, ver Scheuner (1978, p. 174). Rudolf Smend defendia, no célebre Debate de Weimar, a constituição como uma realidade integradora, permanente e contínua (Smend,1994, pp. 189-96).
} 
um plano de transformações sociais e do Estado ${ }^{19}$, fundada na visão de um projeto nacional de desenvolvimento. Esta hipótese poderia explicar a concepção de constituição dirigente adotada pela Assembleia Nacional Constituinte de $1987-1988^{20}$. E o corolário disto seria a visão de que a crise constituinte brasileira seria superada com o cumprimento do projeto constitucional de 1988, que concluiria a construção da nação ${ }^{21}$.

A grande questão, hoje, é a da possibilidade de concretização do projeto constitucional e da conclusão da construção da nação, em um contexto de estado de exceção econômico permanente a que estamos submetidos (Bercovici, 2004d, pp. 167-80; 2008, pp. 307-44). De qualquer modo, é necessária uma nova forma de abordagem da questão do poder constituinte do povo, a partir das contribuições originais de Nelson Saldanha e Paulo Bonavides, vinculando a crise constituinte aos bloqueios da soberania periférica e à interrupção da construção da nação. Pensar a especificidade da manifestação do poder constituinte do povo no Brasil, distinguindo-a das suas congêneres europeias, pode ser um primeiro passo para que, seguindo a constatação de Friedrich Müller (1997, pp. 90-1), o discurso do poder constituinte do povo no Brasil deixe de ser um mero discurso de legitimação da dominação.

Afinal, Raymundo Faoro destacou que nunca, na história brasileira, o poder constituinte do povo conse-

\footnotetext{
${ }^{19}$ Neste sentido da constituição como um plano, ver as considerações de Achterberg (1983).

${ }^{20}$ Para o debate em torno da constituição dirigente, ver Canotilho (2001, pp. V-XXX, 12, 14, 18-24, 27-30, 69-71); Bercovici (1999, pp. 35-51); Streck (2004, pp. 114-45) e Bercovici (2004c, pp. 11-4).

${ }^{21}$ Eu defendi este ponto de vista na conclusão de meu livro Desigualdades regionais, estado e constituição (Bercovici, 2003, pp. 312-5). Neste sentido, poderíamos relembrar as concepções de Peter Häberle, para quem a constituição é expressão também de certo grau de desenvolvimento cultural, um meio de autorrepresentação própria de todo um povo, espelho de sua cultura e fundamento de suas esperanças (Häberle, 1998, pp. 83-90).
} 
guiu vencer o patrimonialismo e o aparelhamento de poder. No entanto, foram as investidas do poder constituinte democrático aquelas que efetivamente desafiaram o establishment (Faoro, 1986, pp. 91-2). Para Faoro, este malogro parcial do poder constituinte no Brasil apenas reforça a luta para a sua revitalização como forma de tentar alterar as nossas problemáticas estruturas políticas e econômico-sociais ${ }^{22}$.

\section{Gilberto Bercovici}

é professor titular da faculdade de direito da USP.

\section{Referências bibliográficas}

ACHTERBERG, N. 1983. "Die Verfassung als Sozialgestaltungsplan". In: (org.), Recht und Staat im sozialen Wandel: Festschrift für Hans Scupin zum 80. Geburstag. Berlin: Duncker \& Humblot, pp.293-315.

AGAMBEN, G. 1995. Homo sacer: il potere sovrano e la nuda vita. Torino: Einaudi.

320 BARROSO, P. H. 1999. Constituinte e constituição: participação popular e eficácia constitucional (1987-1997). Curitiba: Juruá.

BASTID, P. 1970. Sieyès et sa pensée. Paris: Hachette.

BEAUD, O. 1993. "Le souverain". Pouvoirs, n.67, pp.33-45.

1994. La puissance de l'état. Paris: PUF.

BERCOVICI, G. 1999. "A problemática da constituição dirigente: algumas considerações sobre o caso brasileiro”. Revista de Informação Legislativa, n.142, pp.35-51.

2003. Desigualdades regionais, estado e constituição. São Paulo: Max LIMONAD.

2004a. "O estado desenvolvimentista e seus impasses: uma análise do caso brasileiro". Boletim de Ciências Econômicas, v. XLVII, pp.149-180.

2004b. "Teoria do Estado e teoria da constituição na periferia do capitalismo: breves indagações críticas”. In: NUNES, A. J.; COUTINHO, J. N. M. (orgs.). Diálogos constitucionais: Brasil/Portugal. Rio de Janeiro: Renovar, pp.263-290.

2004c. "Constituição e política: uma relação difícil". Lua Nova, n.61, pp.5-24.

\footnotetext{
${ }^{22}$ Em um sentido próximo, ver Tavares (2000, pp.454-7).
} 
2004d. Constituição e estado de exceção permanente: atualidade de Weimar. Rio de Janeiro: Azougue Editorial.

2008. Soberania e constituição: para uma crítica do constitucionalismo. São Paulo: Quartier Latin.

BEYME, K. 1968. Die verfassunggebende Gewalt des Volkes: Demokratische Doktrin und politische Wirklichkeit. Tübingen: Mohr Siebeck.

BIERRENBACH, F. 1986. Quem tem medo da constituinte. Rio de Janeiro: Paz e Terra.

BÖCKENFÖRDE, E.W. 1992a. "Die verfassunggebende Gewalt des Volkes: Ein Grenzbegriff des Verfassungsrechts”. In: Staat, Verfassung, Demokratie: Studien zur Verfassungstheorie und zum Verfassungsrecht. Frankfurt-am-Main: Suhrkamp, pp.90-112. 1992b. "Demokratie als Verfassungsprinzip" In: Staat, Verfassung, Demokratie: Studien zur Verfassungstheorie und zum Verfassungsrecht. Frankfurt-am-Main: Suhrkamp, pp.289-378.

BONAVIDES, P. 1987. Constituinte e constituição: a democracia, o federalismo, a crise contemporânea. Fortaleza: Imprensa Oficial do Ceará. 1998. Curso de direito constitucional. São Paulo: Malheiros. 1999. Do país constitucional ao país neocolonial: a derrubada da constituição e a recolonização pelo golpe de estado institucional. São Paulo: Malheiros.

; ANDRADE, P. 1991. História constitucional do Brasil. Rio de Janeiro: Paz e Terra.

BREUER, S. 1984. "Nationalstaat und Pouvoir Constituant bei Sièyes und Carl Schmitt”. Archiv für Rechts- und Sozialphilosophie, v.70, n.4, pp.495-517. BRITTO, C. A. 2003. Teoria da constituição. Rio de Janeiro: Forense.

CANOTILHO, J. J. G. 2001. Constituição dirigente e vinculação do legislador: contributo para a compreensão das normas constitucionais programáticas. Coimbra: Coimbra.

CANTARO, A. 1994. "Costituzionalismo versus potere costituente?”. Democrazia e Diritto, v.94,n.4/v.95, n.1, pp.139-164.

CLAVREUL, C. 1987. "Sieyès et la genèse de la représentation moderne". Droits, n.6, pp.44-56.

COMPARATO, F. K. 1986. Muda Brasil: uma constituição para o desenvolvimento democrático. São Paulo: Brasiliense.

1989. "Por que não a soberania dos pobres?". In: Para viver a democracia. São Paulo: Brasiliense, pp.61-82.

CRISTI, R. 2000. "The metaphysics of constituent power: Schmitt and the genesis of Chile's 1980 constitution”. Cardozo Law Review, vol.21, pp.1749-75. 
DALLARI, D. A. 1984. Constituição e constituinte. São Paulo: Saraiva.

DANTAS, I. 1985. Poder constituinte e revolução: breve introdução à teoria sociológica do direito constitucional. Bauru: Jalovi.

EUGSTER, M. 1995. Der brasilianische Verfassungsgebungsprozess von 1987/88. Bern/Stuttgart/Wien: Paul Haupt.

FAORO, R. 1986. Assembleia constituinte: a legitimidade recuperada. São Paulo: Brasiliense.

FARIAS, J. F. C. 1988. Crítica à noção tradicional de poder constituinte. Rio de Janeiro: Lumen Juris.

FERRAZ JÚNIOR, T. S. 1986. Constituinte: assembleia, processo, poder. São Paulo: RT.

FERREIRA FILHO, M. G. 1995. Constituição e governabilidade: ensaio sobre a (in) governabilidade brasileira. São Paulo: Saraiva. 1999. O poder constituinte. São Paulo: Saraiva.

FIORAVANTI, M. 1998. Costituzione e popolo sovrano: la costituzione italiana nella storia del costituzionalismo moderno. Bologna: Il Mulino.

FIORI, J. L. 2000. "A propósito de uma 'construção interrompida'”. In: TAVARES, M. C. (org.). Celso Furtado e o Brasil. São Paulo: Perseu Abramo, pp.33-57.

FURTADO, C. 1992. Brasil: a construção interrompida. Rio de Janeiro: Paz e Terra. 1999. "Os caminhos da reconstrução". In: O longo amanhecer: reflexões sobre a formação do Brasil. Rio de Janeiro: Paz e Terra, pp.27-43.

GALLI, C. 1996. Genealogia della politica: Carl Schmitt e la crisi del pensiero politico moderno. Bologna: Il Mulino.

GARCÍA, P.V. 1998. "Mundialización y derecho constitucional: la crisis del principio democrático en el constitucionalismo actual”. Revista de Estudios Políticos, n.100, pp.13-56.

GRAU, E. R. 1985. A constituinte e a constituição que teremos. São Paulo: RT.

GUIMARAENS, F. 2004. O poder constituinte na perspectiva de Antonio Negri: um conceito muito além da modernidade hegemônica. Rio de Janeiro: Forense.

HÄBERLE, P. 1998. Verfassungslehre als Kulturwissenschaft. Berlin: Duncker \& Humblot.

HELLER, H. 1992a. "Sozialismus und Nation". In: Gesammelte Schriften, v.1 Tübingen: Mohr Siebeck, pp.437-526. 1992b. "Politische Demokratie und soziale Homogenität". In: Gesammelte Schriften, v.1. Tübingen: Mohr Siebeck, pp.421-33.

HENKE, W.1968. "Die verfassunggebende Gewalt des Volkes in Lehre und Wirklichkeit”. Der Staat, v.7, pp.165-82. 
1980. "Staatsrecht, Politik und verfassunggebende Gewalt". Der Staat, v.19, pp.181-211.

1992. "Das Ende der Revolution und der Verfassunggebende Gewalt des Volkes”. Der Staat, v.31, pp.265-80.

HOFMANN, H. 2002. Legitimität gegen Legalität: Der Weg der politischen Philosophie Carl Schmitts. Berlin: Duncker \& Humblot.

HORTA, R. M. 1999. Direito constitucional. Belo Horizonte: Del Rey.

ISENSEE, J. 1992. "Verfassungsrecht als 'politisches Recht'”. In: ISENSEE, J.; KIRCHHOF, P. (eds.). Handbuch des Staatsrechts der Bundesrepublik Deutschland. Heidelberg: C. F. Müller Juristischer, v.VII, pp.103-63.

KLEIN, C. 1996. Théorie et pratique du pouvoir constituant. Paris: PUF.

KRÜGER, H. 1973. "Die Verfassung als Programm der nationalen Integration”. In: BLUMENWITZ, D.; RANDELZHOFER, A. (orgs.), Festschrift für Friedrich Berber zum 75. Geburtstag. München: C.H. Beck, pp.247-72.

LASSALLE, F. 1907. "Über Verfassungswesen”. In: Gesamtwerke: Politische Reden und Schriften. Leipzig: Karl Fr. Pfau., vol. 1, pp.40-69

LE PILLOUER, A. 2005. Les pouvoirs non-constituants des assemblées constituantes: essai sur le pouvoir instituant. Paris: Dalloz.

LOEWENSTEIN, K. [1922] 1990. Volk und Parlament nach der Staatstheorie der französischen Nationalversammlung von 1789: Studien zur Dogmengeschichte der unmittelbaren Volksgesetzgebung. Aalen: Scientia.

MÁIZ, R. 1991. "Estado constitucional y gobierno representativo en E. J. Sieyès”. Revista de Estudios Políticos, n.72, pp.45-88.

MÜLLER, F. 1995. Fragment (über) Verfassunggebende Gewalt des Volkes: Elemente einer Verfassungstheorie V. Berlin: Duncker \& Humblot.

1997. Wer ist das Volk? Die Grundfrage der Demokratie: Elemente einer Verfassungstheorie VI. Berlin: Duncker \& Humblot.

NEGRI, A. 2002. Il potere costituente: saggio sulle alternative del moderno. Roma: Manifesto Libri.

OLIVEIRA, M. A. C. 2006. Poder constituinte e patriotismo constitucional: o projeto constituinte do estado democrático de direito na teoria discursiva de Jürgen Habermas. Belo Horizonte: Mandamentos.

PACE, A. 1997. Potere constituente, rigidità costituzionale, autovincoli legislativi. Padova: CEDAM.

PALOMBELLA, G. 1997. Costituzione e sovranità: il senso della democrazia costituzionale. Bari: Edizioni Dedalo.

PASQUINO, P. 1988. "Die Lehre vom 'Pouvoir Constituant' bei Emmanuel Sieyès und Carl Schmitt: Ein Beitrag zur Untersuchung der Grundlagen der modernen Demokratietheorie”. In: QUARITSCH, H. (org.), Complexio Oppositorum: Über Carl Schmitt. Berlin: Duncker \& Humblot, pp.371-85. 
1998. Sieyes et l'invention de la constitution en France. Paris: Odile Jacob.

PILATTI, A. 2008. A Constituinte de 1987-1988: progressistas, conservadores, ordem econômica e regras do jogo. Rio de Janeiro: Ed. da PUC-Rio/ Lumen Juris.

PINTO, L. M. S. C. 1994. Os limites do poder constituinte e a legitimidade material da constituição. Coimbra: Coimbra.

PORTINARO, P.P. 1996."Il grande legislatore e il custode della costituzione”. In: ZAGREBELSKY, G.; et al. Il futuro della costituzione. Torino: Einaudi, pp.5-34.

REDSLOB. R. 1912. Die Staatstheorien der französischen Nationalversammlung von 1789: Ihre Grundlagen in der Staatslehre der Aufklärungszeit und in den englischen und amerikanischen Verfassungsgedanken. Leipzig: Von Veit \& Comp.

REYES, M.A. 1989. Constitución y democracia. Madrid: Tecnos.

ROSANVALLON, P. 2002. O liberalismo econômico: história da ideia de mercado. Bauru: Edusc.

SALDANHA, N. 1986. O poder constituinte. São Paulo: RT.

SCHEUNER, U. 1978. "Verfassung”. In: ; LIST, J. Staatstheorie und Staatsrecht: Gesammelte Schriften. Berlin: Duncker \& Humblot, pp.171-84.

324 SCHMITT, C. 1927. Volksentscheid und Volksbegehren: Ein Beitrag zur Auslegung der Weimarer Verfassung und zur Lehre von der unmittelbaren Demokratie. Berlin/Leipzig: Walter de Gruyter.

1993. Verfassungslehre. Berlin: Duncker \& Humblot.

1996. Politische Theologie: Vier Kapitel zur Lehre von der Souveränität. Berlin: Duncker \& Humblot.

SCHNEIDER, H. P. 1974. "Die Verfassung: Aufgäbe und Struktur". Archiv des öffentlichen Rechts, Sonderheft, pp.64-85.

SIEYÈS, E. J. 1989. Qu'est-ce que le Tiers État? Paris: PUF.

SILVA, J. A. 2000a. Poder constituinte e poder popular: estudos sobre a constituição. São Paulo: Malheiros.

2000b. Curso de direito constitucional positivo. São Paulo: Malheiros.

SMEND, R. 1994. Verfassung und Verfassungsrecht. In: Staatsrechtliche Abhandlungen und andere Aufsätze. Berlin: Duncker \& Humblot, pp.119-276.

STEINER, U. 1966. Verfassunggebung und verfassunggebende Gewalt des Volkes. Berlin: Duncker \& Humblot.

STRECK, L. L. 2004. Jurisdição constitucional e hermenêutica: uma nova crítica do direito. Rio de Janeiro: Forense.

TAVARES, A. R. 2003. Curso de direito constitucional. São Paulo: Saraiva.

TAVARES, M. C. 2000. "Império, território e dinheiro". In: FIORI, J. L. (org.), Estados e moedas no desenvolvimento das nações. Petrópolis: Vozes, pp.449-89. 
THIELE, U. 2003. Advokative Volkssouveränität: Carl Schmitts Konstruktion einer 'demokratischen' Diktaturtheorie im Kontext der Interpretation politischer Theorien der Aufklärung. Berlin: Duncker \& Humblot.

WACHOWICZ, M. 2000. Poder constituinte e transição constitucional. Curitiba: Juruá.

ZWEIG, E. 1909. Die Lehre vom Pouvoir Constituant: Ein Beitrag zum Staatsrecht der französischen Revolution. Tübingen: Mohr Siebeck. 